\title{
Processamento e características de qualidade de hambúrguer de carne de jacaré-do-pantanal (Caiman crocodillus yacare)
}

\section{Processing and quality characteristics of hamburger of Pantanal alligator meat (Caiman crocodillus yacare)}

\author{
Flávia de Oliveira Paulino, ${ }^{*}$ Teófilo José Pimentel da Silva, ${ }^{* *}$ Robson Maia Franco, ${ }^{* *}$ Eliane Teixeira Mársico, ${ }^{* *}$ \\ Anna Carolina Vilhena da Cruz Silva Canto, ${ }^{*}$ Juliana Paulino Vieira, ${ }^{*}$ Ana Paula Amaral de Alcântara Salim Pereira**
}

\begin{abstract}
Resumo
Objetivou-se neste trabalho desenvolver cinco formulações de hambúrguer de carne de jacaré-do-pantanal (Caiman crocodillus yacare) com variações no teor de gordura e na adição de fumaça líquida, como forma de agregar valor na cadeia de derivados cárneos desta espécie. As amostras foram processadas a partir de aparas de carne de jacaré-do-pantanal, obtidas de frigorífico sob o Serviço de Inspeção Federal. Foram produzidos $35 \mathrm{~kg}$ de hambúrgueres com peso médio de $80 \mathrm{~g}$, imediatamente embalados a vácuo e submetidos a processo de congelamento rápido a $-18^{\circ} \mathrm{C} \pm 1^{\circ} \mathrm{C}$. Para 0 controle físicoquímico foram realizadas análises de umidade, proteína, gordura, cinzas, $\mathrm{pH}$, atividade de água $(\mathrm{Aa})$ e valor calórico. No controle bacteriológico dos hambúrgueres foram realizadas contagem de bactérias heterotróficas aeróbias mesófilas, contagem de bactérias heterotróficas aeróbias psicrotróficas, enumeração (determinação do número mais provável) de coliforme total e fecal, contagem e identificação de Staphylococcus coagulase positiva e pesquisa de Salmonella spp. Do ponto de vista físico-químico, a melhor formulação, com baixo valor calórico, foi $5 \%$ de adição de gordura e adição de fumaça, com possibilidade real para o desenvolvimento industrial. Nas análises de bactérias heterotróficas aeróbias mesófilas e psicrotróficas, coliformes totais e fecais, Staphylococcus coagulase positiva e Salmonella spp., todas as amostras se encontravam dentro dos padrões de identidade e qualidade bacteriológica vigentes no Brasil.
\end{abstract}

Palavras-chave: hambúrguer, carne de jacaré-do-pantanal, processamento, qualidade.

\begin{abstract}
The aim of this work was to develop five hamburger formulations of Pantanal alligator meat (Caiman crocodillus yacare) with variations on fat content and liquid smoke addition, as a way to add value adding in the meat food chain of this species. The samples were processed from meat trimmings of Pantanal alligator meat, obtained from a slaughterhouse under Federal Inspection Service. Were produced $35 \mathrm{Kg}$ of hamburgers with mean weight of $80 \mathrm{~g}$, as soon as vaccum packed and subjected to quick freezing process to $-18^{\circ} \mathrm{C} \pm 1^{\circ} \mathrm{C}$. For the physical-chemical control were made analysis of moisture, protein, fat, ash, $\mathrm{pH}$, activity water (Aw) and caloric value. In the bacteriological control of the hamburgers was made count of aerobic mesophilic heterotrophic bacteria, count of psychrotrophic aerobic heterotrophic bacteria, enumeration (determination of most probable number) of total and fecal coliforms, count and identification of positive Staphylococcus coagulase and Salmonella spp. research. From the standpoint of physical-chemical the best formulation, low caloric value, was $5 \%$ of fat addition and liquid smoke addition, with real possibility of industrial development. On the bacteriological analysis of aerobic mesophilic and psychrotrophic heterotrophic bacteria, total and fecal coliforms, positive Staphylococcus coagulase and Salmonella spp., all samples were within identity and bacteriological quality standards in force in Brazil.
\end{abstract}

Keywords: hamburger, Pantanal alligator meat, processing, quality.

\section{Introdução}

Inúmeros pesquisadores têm demonstrado em seus estudos biológicos, nutricionais e tecnológicos que a carne de animais silvestres possui grande potencial para o consumo humano (Rodrigues et al., 2007). Em alguns lugares do mundo, a carne de animais silvestres se caracteriza por ser a principal fonte de proteínas de origem animal. No estado de Dakota do Norte, Estados Unidos, há um grande consumo, e na Nigéria, na década de 1970, 16\%

\footnotetext{
* Programa de Pós-Graduação em Medicina Veterinária da Universidade Federal Fluminense - Área de Concentração: Higiene Veterinária e Processamento Tecnológico de Produtos de Origem Animal (Doutorado) - Rua Vital Brazil Filho, 64. Niterói - RJ. CEP $24230-340$.

** Departamento de Tecnologia dos Alimentos da Faculdade de Veterinária da Universidade Federal Fluminense (UFF).

*** Graduação e Iniciação Científica da Faculdade de Veterinária da UFF.

E-mail: flavia@cca.ufpb.br
} 
dos alimentos de origem animal foram provenientes de animais silvestres (Hoffmann; Romanelli, 1998).

A carne é considerada um alimento nobre para os humanos, pois contribui com proteínas de alto valor biológico, ácidos graxos essenciais e vitaminas do complexo B (Pardi et al., 2001). No entanto, as carnes de animais domésticos apresentam elevados teores de ácidos graxos saturados, considerados responsáveis pela elevação da concentração sérica de colesterol. Contudo, carnes de animais silvestres apresentam reduzidos teores de lipídios totais e altas proporções de ácidos graxos poli-insaturados (Sinclair e Odea, 1990; Skewes et al, 2009; Vicente-Neto et al., 2010). Dentre as carnes não convencionais, atenção tem sido dada à carne de jacaré. Estudiosos têm demonstrado que a carne fresca do jacaré-do-pantanal tem alcançado boa aceitação sensorial, além de possuir potencial tecnológico altamente promissor para a elaboração de derivados (Romanelli et al., 2002).

Mediante a importância e a popularidade do consumo de carnes, a transformação desta matriz alimentícia em produtos industrializados é de suma importância para praticidade, variedade e balanceamento do cardápio. Essa diversificação de oferta inclui os hambúrgueres, que são de fácil preparo e baixo custo. No entanto, torna-se necessária a busca por alimentos alternativos, para aumentar e suprir a demanda mundial. As fontes alternativas de alimentos devem ser nutritivas, possuir boas características sensoriais e ser de baixo custo, para atingir grande parte da população. Dessa forma, um aproveitamento mais dirigido de subprodutos de animais abatidos poderá ser utilizado em forma de consumo direto pelos seres humanos (Romanelli e Schmidt, 2003).

Objetivou-se com este trabalho produzir um derivado cárneo a base de carne de jacaré-do-pantanal (Caiman crocodillus yacare) como forma de aproveitamento de aparas ou recortes de desossa com baixo valor de mercado na cadeia de produção desta espécie, avaliar o efeito da adição de gordura suína e da fumaça líquida, através dos parâmetros físicoquímicos e bacteriológicos dos hambúrgueres formulados.

\section{Material e métodos}

Para a produção de hambúrgueres de jacaré foi utilizada como matéria-prima aparas ou recortes cárneos provenientes da desossa das patas, dorso e cauda de jacaré-do-pantanal (Caiman crocodillus yacare). A matéria-prima foi obtida em frigorífico sob o Serviço de Inspeção Federal no estado do Mato Grosso. A carne foi devidamente embalada a vácuo e congelada rapidamente à temperatura de $-18^{\circ} \mathrm{C} \pm 1^{\circ} \mathrm{C}$. $\mathrm{O}$ transporte até o Laboratório de Tecnologia de Carnes da Faculdade de Veterinária da Universidade Federal Fluminense (UFF) foi por via aérea, sendo mantidas as condições de estocagem. A gordura suína utilizada foi papada suína, obtida em hipermercado no município de Niterói, RJ e devidamente acondicionada a $4^{\circ} \mathrm{C} \pm 1^{\circ} \mathrm{C}$, até o preparo das formulações. Todos os ingredientes foram transportados até o Laboratório de Tecnologia de Alimentos do SENAI, localizado em Vassouras, estado do Rio de Janeiro.

Para o experimento foram utilizadas cinco formulações com duas variáveis: gordura e fumaça. A formulação Controle não apresentou adição de gordura nem de fumaça líquida. As formulações seguiram a seguinte padronização: formulação F1 possuía $5 \%$ de gordura suína sem adição de fumaça líquida; F2 apresentou 5\% de gordura suína com adição de 0,3\% de fumaça líquida; F3 possuía 10\% de gordura suína sem adição de fumaça líquida e F4 apresentou $10 \%$ de gordura suína com presença de $0,3 \%$ de fumaça líquida. Para cada tratamento foram produzidos $7 \mathrm{~kg}$ de hambúrguer, totalizando $35 \mathrm{~kg}$.

Após descongelamento e seleção da matéria-prima procedeu-se a moagem da carne, pesagem dos ingredientes e homogeneização em máquina apropriada. Os ingredientes utilizados foram aparas de carne de jacaré (80,15\%-85,45\%), gordura suína (5,00-10,00\%), proteína texturizada de soja $(4,00 \%)$, fumaça líquida $(0,30 \%)$, água $(2,00 \%)$, eritorbato de sódio $(0,025 \%)$, tripolifosfato de sódio $(0,025 \%)$, sal $(1,80 \%)$, alho em pasta $(0,50 \%)$, cebola $(1,00 \%)$, pimenta-do-reino branca $(0,10 \%)$ e noz-moscada $(0,10 \%)$. Os hambúrgueres foram produzidos manualmente, com peso aproximado de $80 \mathrm{~g}$, e foram imediatamente submetidos ao processo de congelamento rápido a $-18^{\circ} \mathrm{C} \pm 1^{\circ} \mathrm{C}$ durante uma hora. As amostras foram devidamente embaladas em sacos de polietileno de baixa densidade a vácuo, identificadas e congeladas. Os hambúrgueres prontos retornaram para 0 Laboratório de Tecnologia de Carnes da UFF, em caixas isotérmicas, onde permaneceram congelados a $-12^{\circ} \mathrm{C} \pm 1^{\circ} \mathrm{C}$ até a realização das análises laboratoriais.

As análises físico-químicas foram realizadas em triplicata. Foram determinados os teores de umidade em estufa a $105^{\circ} \mathrm{C}$, proteína por Kjeldahl, gordura total pelo método de Soxhlet e cinzas em forno mufla a $550^{\circ} \mathrm{C}$, segundo metodologia recomendada pela AOAC (1995). Para a determinação de $\mathrm{pH}$ utilizou-se método potenciométrico recomendado pelo LANARA (Brasil, 1981). A atividade de água foi determinada no dia de fabricação das amostras, antes da estocagem em congelador. Para isso utilizou-se o aparelho "Pawkit ${ }^{\circledR}$ " (Decagon Devices, Inc., USA). O cálculo do valor calórico dos hambúrgueres foi obtido multiplicando-se o teor de lipídios por $9,1 \mathrm{kcal} / \mathrm{g}$ e o teor de proteínas e carboidratos por $4,1 \mathrm{kcal} /$ g, segundo metodologia de Keeton (1991). Os resultados foram somados e obteve-se o valor calórico de cada formulação utilizando a unidade de kcal/100g.

Para o julgamento das análises bacteriológicas foi seguido o padrão determinado pela ANVISA (Brasil, 2001). Foram realizadas análises de Coliformes a $45^{\circ} \mathrm{C}$ (Franco e Mantilla, 2004), Estafilococos coagulase positiva (Brasil, 2003) e Salmonella spp. (Pignato et al., 1995). Além das análises oficiais inclusas em Brasil, 2001, realizou-se também contagem de bactérias heterotróficas aeróbias mesófilas e psicrotróficas (Brasil, 2003), para indicação da qualidade higiênica dos hambúrgueres.

Os dados obtidos foram analisados através do software estatístico SISVAR versão 4.0 (Ferreira, 2000) com nível de significância de $5 \%$, e quando apresentada diferença significativa aplicou-se o teste de Tukey.

\section{Resultados e discussão}

Os dados referentes à composição centesimal e valor calórico das formulações podem ser vistos na Tabela 1. Dentre as formulações testadas, a formulação Controle obteve o maior teor de proteína e menor de gordura entre as formulações testadas. A justificativa para tal fato é que nessa formulação não houve adição de gordura externa, mantendo 
Tabela 1: Valores médios e desvio-padrão da composição centesimal (umidade, proteína, lipídios e umidade) dos hambúrgueres de carne de jacaré-do-pantanal (Caiman crocodillus yacare) das diferentes formulações (Controle, F1, F2, F3 e F4)

\begin{tabular}{cccccc}
\hline Tratamentos & $\begin{array}{c}\text { Umidade } \\
(\%)\end{array}$ & $\begin{array}{c}\text { Proteína } \\
(\%)\end{array}$ & $\begin{array}{c}\text { Lipídios } \\
(\%)\end{array}$ & $\begin{array}{c}\text { Cinzas } \\
(\%)\end{array}$ & $\begin{array}{c}\text { Valor Calórico } \\
(\mathbf{1 0 0 g})\end{array}$ \\
\hline Controle & $73,95^{\mathrm{a}} \pm 0,15$ & $23,18^{\mathrm{a}} \pm 0,67$ & $1,05^{\mathrm{a}} \pm 0,13$ & $1,46^{\mathrm{a}} \pm 0,04$ & $106 \mathrm{Kcal}$ \\
F1 & $70,55^{\mathrm{b}} \pm 0,92$ & $21,28^{\mathrm{b}} \pm 0,88$ & $6,27^{\mathrm{b}} \pm 0,12$ & $1,36^{\mathrm{a}} \pm 0,04$ & $147 \mathrm{Kcal}$ \\
F2 & $71,11^{\mathrm{b}} \pm 0,07$ & $21,23^{\mathrm{b}} \pm 0,62$ & $6,17^{\mathrm{b}} \pm 0,13$ & $1,38^{\mathrm{a}} \pm 0,06$ & $144 \mathrm{Kcal}$ \\
F3 & $70,00^{\mathrm{b}} \pm 0,49$ & $17,06^{\mathrm{c}} \pm 0,61$ & $11,30^{\mathrm{c}} \pm 0,18$ & $1,23^{\mathrm{c}} \pm 0,01$ & $174 \mathrm{Kcal}$ \\
F4 & $69,95^{\mathrm{c}} \pm 0,58$ & $16,71^{\mathrm{c}} \pm 0,62$ & $11,47^{\mathrm{c}} \pm 0,23$ & $1,24^{\mathrm{bc}} \pm 0,01$ & $175 \mathrm{Kcal}$
\end{tabular}

Controle = ausência de gordura e de fumaça. $\mathrm{F} 1=5 \%$ de gordura, ausência de fumaça. $\mathrm{F} 2=5 \%$ de gordura, 0,3\% fumaça líquida, F3 = 10\% de gordura, ausência de fumaça. F4 = 10\% de gordura, $0,3 \%$ de fumaça. $a, b, c$ Médias na mesma coluna seguidas de diferentes letras diferem significativamente entre si $(p<0,05)$. de cinzas. Esses valores foram considerados muito bons, principalmente em relação ao teor de gordura, com menos de $1 \%$ de lipídios totais. Estes valores são próximos aos encontrados na formulação Controle do presente estudo e o que leva a sugerir que carnes não convencionais possuem bom apelo nutricional, permitindo a inserção de derivados no mercado consumidor. No entanto, é válido ressaltar que a análise de ácidos graxos que compõe esses produtos deve ser realizada.

os baixos níveis de gordura e alto nível proteico naturais da carne de jacaré. As formulações F1 e F2, ambas com $5 \%$ de adição de gordura, não apresentaram diferença estatística ( $p>0.05)$ entre elas em relação ao nível de proteínas, obtendo, respectivamente, $21,28 \%$ e $21,23 \%$. Essas formulações também não apresentaram diferença significativa ao nível de $5 \%$ em relação à gordura, cujos teores foram de $6,27 \% \mathrm{e}$ $6,17 \%$, respectivamente. No entanto, as formulações F3 e F4, que receberam adição de $10 \%$ de gordura externa apresentaram redução relativa do teor proteico quando comparadas às demais formulações. Os teores proteicos para essas formulações foram de $17,06 \%$ e $16,71 \%$, respectivamente. Os teores de gordura foram significativamente $(p<0,05)$ mais elevados quando comparado às demais formulações, porém não foram significativamente diferentes entre si. Resultados de $11,30 \%$ e $11,47 \%$ de gordura para F3 e F4, respectivamente, se mostraram quase duas vezes maiores aos observados em F1 e F2.

Os teores de umidade das cinco formulações se mantiveram na faixa entre $69,95 \%$ e $73,95 \%$, sendo significativo o tratamento controle comparado aos demais tratamentos com adição de gordura. No entanto, esses valores são considerados normais para este tipo de derivado cárneo. Em relação às cinzas, os valores entre $1,23 \%$ e $1,46 \%$ também são considerados normais para derivado cárneo do tipo hambúrguer.

Estudo correlacionado foi realizado por Pinto et al. (2007), que analisaram o potencial tecnológico da carne de capivara e desenvolveram alguns derivados cárneos, entre os quais o hambúrguer. Os resultados médios da composição centesimal encontrados no hambúrguer de capivara foram $58,7 \%$ de umidade, $14,4 \%$ de proteína, $20,4 \%$ de gordura e $2,9 \%$ de cinzas. Os valores médios de proteína e gordura desse hambúrguer discordam dos encontrados neste trabalho, que se manteve na faixa de 16,71 a $21,28 \%$ de proteína e de 1,05 a $11,47 \%$ de gordura. Esta diferença provavelmente ocorreu em função da adição de $25 \%$ de gordura suína na formulação do hambúrguer desses autores.

Contudo, Gonçalves e Otta (2008), ao estudarem o potencial de exploração da carne de rã-touro no Rio Grande do Sul verificaram que os hambúrgueres produzidos a partir desta espécie apresentavam $79,20 \%$ de umidade, $16,60 \%$ de proteínas, $3,30 \%$ de carboidratos, $0,33 \%$ de lipídios e $0,20 \%$
O valor calórico verificado nesse estudo foi reflexo direto da quantidade de gordura adicionada. Logo, a formulação Controle, que não foi adicionada de gordura externa, obteve o menor valor calórico, com aceitáveis $106 \mathrm{kcal} / 100 \mathrm{~g}$ de produto. Este valor subiu quase $50 \%$ quando adicionado $5 \%$ de gordura suína (Tabela 1). Valores calóricos de $147 \mathrm{kcal} / 100 \mathrm{~g}$ produto e $144 \mathrm{kcal} / 100 \mathrm{~g}$ produto foram observados para nas formulações F1 e F2, respectivamente. Contudo, quando adicionado $10 \%$ de gordura suína, obtevese aumento de aproximadamente $70 \%$ do valor calórico quando comparado à formulação controle. Valores calóricos elevados não são desejáveis principalmente por dois motivos: descaracterização da carne de jacaré, considerada magra; e alteração sensorial do produto.

$\mathrm{Na}$ Tabela 2 constam os valores de atividade de água e $\mathrm{pH}$ para as formulações testadas. Em relação à atividade de água (Aa) os valores situaram-se entre 0,89 e 0,93 . Em relação ao $\mathrm{pH}$ os valores situaram-se entre 5,7 e 5,9. Estes resultados estão em concordância com os dados obtidos por Santillán e Morales (1991) que estudaram a produção de hambúrguer de carpa com redução da atividade de água e $\mathrm{pH}$ final entre 5,5-6,0. As formulações F1 e F2 resultaram em menor Aa do que a Controle; Controle, F1 e F2 não possuíram diferença significativa entre si. Considerando-se o produto cárneo alvo

Tabela 2: Valores médios e desvio padrão de $\mathrm{Aa}$ e $\mathrm{pH}$ dos hambúrgueres de carne de jacaré-do-pantanal (Caiman crocodillus yacare) das diferentes formulações (Controle, F1, F2, F3 e F4)

\begin{tabular}{ccc}
\hline \multirow{2}{*}{ Tratamentos } & \multicolumn{2}{c}{ Parâmetros } \\
\cline { 2 - 3 } & $0,93^{\mathrm{a}} \pm 0,11$ & $\mathbf{p H}$ \\
\hline Controle & $0,91^{\mathrm{b}} \pm 0,15$ & $5,7^{\mathrm{a}} \pm 0,17$ \\
F1 & $0,91^{\mathrm{a}} \pm 0,19$ & $5,8^{\mathrm{ab}} \pm 0,22$ \\
F2 & $0,90^{\mathrm{c}} \pm 0,21$ & $5,8^{\mathrm{a}} \pm 0,12$ \\
F3 & $0,89^{\mathrm{c}} \pm 0,18$ & $5,9^{\mathrm{b}} \pm 0,10$ \\
F4 & $5,9^{\mathrm{b}} \pm 0,25$ \\
\hline
\end{tabular}

Controle $=$ ausência de gordura e de fumaça. $\mathrm{F} 1=5 \%$ de gordura, ausência de fumaça. $\mathrm{F} 2=5 \%$ de gordura, $0,3 \%$ fumaça líquida, $\mathrm{F} 3=10 \%$ de gordura, ausência de fumaça. F4 $=10 \%$ de gordura, $0,3 \%$ de fumaça.

a,b,c Médias na mesma coluna seguidas de diferentes letras diferem significativamente entre si $(p<0,05)$. 
deste estudo, observou-se que quanto menor a $\mathrm{Aa}$ e o $\mathrm{pH}$ melhor é a qualidade da amostra, uma vez que Aa e pH elevado pode ser forte indicativo de crescimento bacteriano e, consequentemente, menor validade comercial do produto.

Em relação à contagem microbiana, quando os parâmetros utilizados foram coliformes a $45^{\circ} \mathrm{C}$, Staphylococcus coagulase positiva e Salmonella spp todas as amostras encontraram-se adequadas quando comparadas à legislação vigente. $\mathrm{Na}$ contagem de bactérias heterotróficas aeróbias mesófilas e bactérias heterotróficas aeróbias psicrotróficas os resultados máximos encontrados foram 2,5 $\times 10^{3} \mathrm{UFC} / \mathrm{g}$ e $2,2 \times 10^{3} \mathrm{UFC} / \mathrm{g}$, respectivamente. Tais valores foram considerados satisfatórios e que as amostras realizadas possuíam qualidade higiênico-sanitária na produção dos hambúrgueres.

\section{Conclusões}

A formulação de hambúrguer que mais se destacou do ponto de vista físico-químico foi a que apresentou 5\% de adição de gordura e adição de fumaça líquida. Nessa formulação obtiveram-se os melhores resultados gerais e destacou-se em relação às demais formulações, tornando-se a principal formulação com possibilidade real para desenvolvimento industrial.

Dentro das análises bacteriológicas todas as amostras apresentaram-se adequadas em relação à legislação vigente e, portanto, não representam risco à saúde do consumidor.

Sugerem-se estudos de aceitação sensorial para verificar o potencial mercadológico desses produtos.

\section{Agradecimentos}

Ao Centro de Tecnologia de Alimentos e Bebidas do Serviço Nacional da Indústria (SENAI), localizado em Vassouras-RJ, pela oportunidade de realizar a etapa experimental em suas instalações físicas.

\section{Referências}

ASSOCIATION OF OFFICIAL ANALYTICAL CHEMISTS. Official methods of analysis of the Association of Official Analytical Chemists. 16. ed. Arlington, 1995.

BRASIL. Ministério da Agricultura. Secretaria Nacional de Defesa Agropecuária. Laboratório Nacional de Referência Animal (LANARA). Métodos Analíticos Oficiais para Controle de Produtos de Origem Animal e Seus Ingredientes. II. Métodos Físico-Químicos. Aprovado pela Portaria no 001 de 07/10/1981. Brasília, 123 p. 1981.

BRASIL. Ministério da Saúde. Agência Nacional de Vigilância Sanitária. Resolução RDC no12 de 02 de janeiro de 2001. Aprova o Regulamento Técnico sobre padrões microbiológicos para alimentos. Disponível em: <http://www.anvisa.gov.br/legis/resol/12_01rdc.htm>. Acesso em 25 de julho de 2011.

BRASIL. Ministério da Agricultura, Pecuária e Abastecimento. Instrução Normativa $\mathrm{n}^{\circ} 62$, de 26 de agosto de 2003. Oficializa os Métodos Analíticos Oficiais para Análises Microbiológicas para Controle de Produtos de Origem Animal e Água (MAPA). Diário Oficial República Federativa do Brasil, Brasília, DF, p. 14, 18 set. 2003. Seção 1.

FERREIRA, D.F. Análises estatísticas por meio do Sisvar para o Windows versão 4.0. In: Reunião Anual da Região Brasileira da Sociedade Internacional de Biometria, 45, 2000, São Carlos. Anais... São Carlos: UFSCar, p. 255-258, 2000.

FRANCO, R.M.; MANTILLA, S.P.S. Escherichia coli em cortes de carne bovina (acém): avaliação de metodologia e sensibilidade de antimicrobianos aos sorovares predominantes. In: SEMINÁRIO DE INICIAÇÃO CIENTÍFICA E PREMIO UFF VASCONCELOS TORRES DE CIÊNCIA E TECNOLOGIA, 14, 2004, Rio de Janeiro. Anais... Rio de Janeiro: UFF, 2004. CD.

GONÇALVES, A.A.; OTTA, M.C.M. Aproveitamento da carne da carcaça de rã-touro gigante no desenvolvimento de hambúrguer. Revista Brasileira de Engenharia de Pesca, v. 3, n. 2, p. 7-15, jul. 2008.

HOFFMAN, F.L.; ROMANELLI, P.F. Análise microbiológica da carne de jacaré- do-pantanal (Caiman crocodillus yacare). Ciência e Tecnologia de Alimentos, Campinas, v. 19, n. 3, p. 258-264, ago./out. 1998.

KEETON, J.T. Fat substitutes and fat modification in processing. Reciprocal Meats Conference Proceedings, Manhattan, v. 44, p. 7991, 1991.
PARDI, M.C.; SANTOS, I.F.; SOUZA, E.R.; PARDI, H.S. Ciência, higiene e tecnologia da carne: tecnologia da sua obtenção e transformação. Goiânia: Universidade Federal de Goiás, v. 1, 623 p. 2001.

PIGNATO, S.; MARINO, A.; EMANUELE, M.; IANNOTTA, V.; CARACAPPA, S.; GIAMMANCO, G. Evaluation of New Culture Media for Rapid Detection and Isolation of Salmonellae in foods. Applied and Environmental Microbiology, v. 61, n. 5, p. 1996-1999, 1995.

PINTO, M.F.; PONSANO, E.H.G.; ALMEIDA, A.P.S.; HEINEMANNIV, R.J.B.; SOUZA, W.M. Características e potencial tecnológico da carne da capivara. Ciência Rural, Santa Maria, v. 37, n. 3, p. 868-873, mai./ jun. 2007.

RODRIGUES, E.C.;BRESSAN, M.C.; VICENTE NETO, J.V.; VIEIRA, J.O.; FARIA, P.B.; FERRÃO, S.P.B.; ANDRADE, P.L. Qualidade e composição química de cortes comerciais de carne de jacaré-do-pantanal (Caiman yacare) Ciência e Agrotecnologia., Lavras, v. 31, n. 2, p. 448-455, mar./abr. 2007.

ROMANELLI, P.N.; SCHMIDT, J. Estudo do aproveitamento das vísceras do jacaré do pantanal (Caiman crocodilus yacare) em farinha de carne. Ciência e Tecnologia de Alimentos, Campinas, v. 23, n.10, p.131-139, dez. 2003.

ROMANELLI, P.N.; CASERI, R.; LOPES FILHO, J.F. Processamento da carne do jacaré-do-pantanal (Caiman crocodilus yacare). Ciência e Tecnologia de Alimentos, Campinas, v. 22, n. 1, p. 70-75, jan.-abr. 2002.

SANTILLÁN, L.; MORALES, L.J. Production of a carp-hamburger-like product by reducing the water activity. Archivos Latinoamericanos de Nutrición, v.42, n. 2, p. 173-179,1992.

SINCLAIR, A.J.; ODEA, K. Fats in human diets through history: is the western diet out of step? In: WOOD, J.D.; FISHER, A.V. Reducing fat in meat animals. London: Elsevier, 1990, p. 1-47.

SKEWES O.; MORALES,R; MENDOZA,N.; C, SMULDERS, F.J.M.; PAULSEN, P. Carcass and meat quality traits of wild boar (Sus scrofa s. L.) with $2 n=36$ karyotype compared to those of phenotypically similar crossbreeds $(2 n=37$ and $2 n=38)$ raised under the same farming conditions Fatty acid profile and cholesterol. Meat Science, v. 83, n. 2, p.195-200, 2009.

VICENTE-NETO, J.; BRESSAN, M.C.; FARIA, P.B.; VIEIRA, J.D.; CARDOSO, M.G.; GLÓRIA, M.B.A.; GAMA, L.T. Fatty acid profiles in meat from Caiman yacare (Caiman crocodilus yacare) raised in the wild or in captivity. Meat Science, v. 85, n. 4, p. 752-758, 2010. 